\title{
ECONOMETRIC IDENTIFICATION OF THE IMPACT OF REAL ESTATE CHARACTERISTICS BASED ON PREDICTIVE AND STUDENTIZED RESIDUALS
}

\author{
Mariusz Doszyń, Ph.D. assoc. prof. \\ Katedra Ekonometrii \\ Uniwersytet Szczecinski \\ e-mail:mariusz.doszyn@wneiz.pl

\section{Sebastian Gnat, Ph.D.} \\ Katedra Badań Operacyjnych i Zastosowań Matematyki w Ekonomii \\ Uniwersytet Szczecinski \\ e-mail: sebastian.gnat@usz.edu.pl
}

\begin{abstract}
The paper proposes a means of determining the impact of real estate characteristics based on the residuals of an accordingly specified econometric model. The econometric model contains explanatory variables whose values are easily measurable. Then, the hypothesis that the residuals of the econometric model encompass the impact of specific factors indicating that the real estate is atypical is verified, thus supporting real estate market analysis. The work describes various types of residuals (predictive and studentized residuals).
\end{abstract}

Key words: identification of specific (unobserved) factors, predictive and studentized residuals, econometric analysis of real estate market.

JEL Classification: C01, R30.

Citation: Doszyń M., Gnat S., 2017, Econometric Identification of the Impact of Real Estate Characteristics Based on Predictive and Studentized Residuals, Real Estate Management and Valuation, vol. 25, no. 1, pp. 84-92.

DOI: $10.1515 /$ remav-2017-0005

\section{Background}

An essential stage of the real estate valuation procedure is market analysis. According to the regulation of the Council of Ministers on property valuation and the development of the Valuation Report, the valuer, first of all, takes into consideration the going prices, rents and transaction conditions. The interpretative note on the comparative approach to the real estate valuation includes a statement that the valuer applying this approach should assess the usability of the identified transaction prices in terms of their possible importance to the valuation process. The usefulness of information collected by the valuer is associated, inter alia, with the possible occurrence of particular transaction conditions that can result in the actual price deviating grossly from the average market prices. The term of particularity or, in other words, specificity does not necessarily refer solely to the transaction conditions. An individual property can also be characterized by certain not readily apparent attributes that can lead to a situation where prices of properties with similar, or even identical, identified market characteristics will differ. In the process of real estate valuation, the valuer should take into consideration information that is typical and does not differ significantly from the 
average prices. The legal regulations and the General National Rules of Valuation provide no clear definition of the terms: grossly deviate from the average and an atypical real estate. The definition of $a$ similar property in the Act on Real Estate Management is controversial and leaves room for individual interpretations that can lead to different conclusions. The only instance when the legislature clearly indicates the border of atypicality is $\S 5$. 2. of the aforementioned regulation, stating that, in the valuation process, we should reject prices obtained in a sale by tender that differ more than by $20 \%$ from the market prices of similar properties. Prof. E. Kucharska-Stasiak points to difficulties in capturing appropriate information from the real estate market: "real properties available on the market are heterogeneous and have diverse attributes. (...) the distribution of prices of individual real estate attributes on the market is not known" (KUCHARSKA-STASIAK 2010). This means that it is difficult to perform some parts of market analysis based on collected data so that the interrelations occurring on the market can be correctly identified. As a result of the above-mentioned conditions of both a legal and market nature, it seems essential to create a method that could help, in the most objective way possible, to single out transactions that can be regarded as atypical from the set of transactions identified in the course of a market analysis. In the present study, the transactions considered to be atypical are the ones that are influenced by undisclosed or difficult to observe specific characteristics of a marketed property. The paper proposes a way to determine the impact of specific attributes of a traded property using the residuals of an adequately specified econometric model. The application of diverse statistical and econometric methods is quite common in real estate market analysis, both in foreign (see ARSLAN et al. 2015, BIN 2004, PARDOE 2008) and Polish scientific publications (e.g. CELLMER and SZCZEPANKOWSKA 2015, CiCHOCIŃSKI and DĄBROWSKI 2013). Still, the analytical method proposed here has, so far, not been used in real estate market analysis. The econometric model used in the paper contains explanatory variables whose values are easily measurable. Subsequently, the hypothesis that the residuals of an econometric model contain the impact of specific factors that make the traded property atypical is verified, thus supporting the process of real estate market analysis. In the study, predictive and studentized residuals are outlined and used. The research was carried out on 19 sales transactions of vacant plots of land situated in one of the housing developments in Szczecin.

\section{Research Methodology}

The method of identifying the impact of directly non-observable factors based on appropriate model residuals has been taken from (DoszYŃ 2013) where, in the context of a study on the impact of human propensities on economic phenomena, he describes, in detail, the possibility of using the least squares, predictive, studentized, recursive and BLUS residuals for this purpose. He also outlines the advantages and disadvantages of the individual types of residuals. In the present paper, the specific attributes of a property are identified by means of predictive and studentized residuals. Such residuals can be determined in several ways (see: DosZYŃ 2013).

In small samples, least squares residuals are heteroscedastic and autocorrelated, even when these phenomena do not actually occur. The shortcoming of least squares residuals is the fact that, when verifying the hypothesis of an i-th residual that is significantly different from zero, we calculate the standard deviation of residuals by means of, inter alia, the observed residual. This defect does not occur in the case of predictive, studentized and recurrent residuals. In calculating predictive and studentized residuals, the reference point are all of the objects except for the analyzed one. In the case of the recurrent residuals, the set of observations is sequential. From the theoretical point of view, the best properties have recursive or BLUS residuals. It is to their disadvantage, however, that the residuals for all the objects cannot be calculated. As for recurrent residuals, we cannot estimate a few initial ones due to the "starter observations" that are necessary to estimate the first, sequential model. On the other hand, the number of BLUS residuals is diminished by the number of estimated model parameters, so they cannot be calculated for all the objects (real properties). All these shortcomings may be of great significance when samples are small, as was the case in this study.

In order to determine the predictive residuals we can use the artificial dummy variable $z_{i}$. The variable $z_{i}=1$ in the case of the $i$-th property, and $z_{i}=0$ - in the remaining cases, where $i=1,2, \ldots, n(n-$ number of properties). The given variable $z_{i}$ adopts the value of one for only one property (with index $i$ ), while there are as many variables $z_{i}$ as there are properties.

Subsequently, we estimate the parameters for the following models: 


$$
y_{i}=\sum_{j=0}^{k} \alpha_{j} x_{j i}+\gamma_{i} z_{i}+u_{i}
$$

where:

$y_{t} \quad$ - the dependent variable (the unit price of a property),

$x_{j t} \quad$ - the explanatory variables (the property attributes) $(j=0,1, \ldots, k)$,

$z_{i} \quad$ - the dummy variables $(i=1,2, \ldots, n)$,

$a_{f}, \gamma_{t}$ - the structural parameters,

$u_{t} \quad-$ the random factor.

We estimate as many models as there are properties $(n)$, and we determine $p_{t}$ for each property:

$$
\begin{aligned}
& y_{i}=\sum_{j=0}^{k} \alpha_{j} x_{j i}+\gamma_{1} z_{1}+u_{i} \\
& y_{i}=\sum_{j=0}^{k} \alpha_{j} x_{j i}+\gamma_{1} z_{2}+u_{i} \\
& \ldots \ldots \\
& y_{i}=\sum_{j=0}^{k} \alpha_{j} x_{j i}+\gamma_{n} z_{n}+u_{i}
\end{aligned}
$$

In model (2), in order to simplify the notation, identical symbols of parameters $\left(\alpha_{j}\right)$ with the property attributes $\left(x_{j i}\right)$ and random factor $\left(u_{i}\right)$ have been adopted in every equation. The estimates of parameters $\gamma_{i}$ for individual properties are the predictive residuals, while the values of $\mathrm{t}$-Student statistics that have been determined for them are the studentized residuals. On their basis, we will identify the real properties for which the hypothesis of possessing specific attributes is verified. The value of a predictive residual for a given property provides additional information about the power of this influence. We should bear in mind, however, that this procedure poses problems associated with econometric modeling based on data mining (CHAREMZA \& DEADMAN 1997). This applies to the actual rather than nominal values of statistical significance levels in the process of verifying statistical hypotheses.

\section{Empirical Study}

One of the challenges faced by real estate market analysts or valuers is the absence of information about properties that tend to be strongly diversified in terms of their value-influencing factors. Even if information typically taken into account in evaluating property attributes is available, many properties can still have their own unique qualities. These specific factors can affect the price, thus influencing (distorting) the valuation results. In this study, an attempt is made to apply econometric methods in identifying the impact of such specific factors on property price.

In the first stage, the following econometric model is estimated. In this model, the dependent variable is the price of $1 \mathrm{~m}^{2}\left(c_{t}\right)$ of a plot of land, while the explanatory variables are:

1. Accessibility ( 1 - inconvenient, 2 - medium, 3 - convenient),

2. Technical Infrastructure Facilities $(0$ - incomplete, 1 - complete $)$ - denoted as $w_{t}$

3. Use Regime and Purpose (1 - weak, 2 - medium, 3 - good, 4 - very good) - denoted as $u z_{t}$

4. Size (1 - large, 2 - medium, 3 - small),

5. Location and Neighborhood ( 0 - unsatisfactory, 1 - average),

6. Topography and Condition of Property ( 0 - unsatisfactory, 1 - satisfactory).

The choice of attributes depends mainly on the data available in the transaction database. The database covers 19 sales transactions of vacant plots of land being the objects of ownership rights. The transactions were concluded in one of the housing developments in Szczecin over a span of one year. 
The majority of (potential) explanatory variables are expressed on an ordinal scale. Three of them $(2,5$ and 6) are dichotomous variables measured on a nominal scale. Table 1 shows the analyzed properties with reference to the values of individual value-influencing factors. It is worth adding that the choice of factors and the specification of their values had been developed by real estate valuers who prepared the valuation report from which the transaction database used in this study was taken.

Table 1

Description of analyzed properties with reference to their specified value-influencing factors

\begin{tabular}{|c|c|c|c|c|c|c|c|}
\hline \multirow[b]{2}{*}{ Property } & \multirow[b]{2}{*}{ Price of 1 sqm } & \multicolumn{6}{|c|}{ Number of factor } \\
\hline & & 1 & 2 & 3 & 4 & 5 & 6 \\
\hline 1 & 184.43 & 1 & 0 & 1 & 1 & 0 & 0 \\
\hline 2 & 211.81 & 1 & 0 & 2 & 3 & 0 & 0 \\
\hline 3 & 215.67 & 1 & 0 & 2 & 2 & 0 & 0 \\
\hline 4 & 217.50 & 2 & 1 & 2 & 2 & 1 & 0 \\
\hline 5 & 219.30 & 2 & 0 & 3 & 3 & 0 & 0 \\
\hline 6 & 219.88 & 2 & 0 & 2 & 3 & 0 & 0 \\
\hline 7 & 233.01 & 2 & 1 & 3 & 3 & 1 & 0 \\
\hline 8 & 234.56 & 2 & 1 & 2 & 3 & 0 & 0 \\
\hline 9 & 250.00 & 3 & 1 & 3 & 2 & 1 & 0 \\
\hline 10 & 250.00 & 3 & 1 & 3 & 2 & 1 & 0 \\
\hline 11 & 251.72 & 3 & 1 & 3 & 3 & 1 & 1 \\
\hline 12 & 253.07 & 2 & 1 & 3 & 3 & 1 & 0 \\
\hline 13 & 257.14 & 3 & 1 & 3 & 2 & 0 & 0 \\
\hline 14 & 258.62 & 3 & 1 & 3 & 3 & 1 & 0 \\
\hline 15 & 258.90 & 3 & 1 & 3 & 3 & 1 & 0 \\
\hline 16 & 269.64 & 3 & 1 & 4 & 3 & 1 & 1 \\
\hline 17 & 270.00 & 3 & 1 & 4 & 3 & 1 & 1 \\
\hline 18 & 272.73 & 3 & 1 & 4 & 2 & 1 & 1 \\
\hline 19 & 274.19 & 3 & 1 & 4 & 3 & 1 & 1 \\
\hline
\end{tabular}

Source: own study.

At the statistical significance level $(\alpha=0.05)$, a hypothesis that the parameter does not differ significantly from zero should be rejected only in the case of two variables (2 and 3 ). After its parameters have been estimated, the model is written as:

$$
\hat{c}_{t}=168.199+19.420 w_{t}+21.009 u z_{t}, \bar{R}^{2}=0.904, S_{e}=7.784
$$

According to the obtained results, if the property is fully equipped with technical infrastructure facilities, its unit price is higher by an average of $19.42 \mathrm{zl} / \mathrm{m}^{2}$, after taking into consideration the principle of ceteris paribus. As we move to the better option of Use Regime and Purpose, the unit price increases by $21.01 \mathrm{zl} / \mathrm{m}^{2}$ on average, ceteris paribus. The value of the corrected coefficient of determination indicates very good fit of theoretical values to the empirical ones.

Apart from the linear form of the model, its analytical log-linear form was also tested. However, in the case of the real estate analyzed here, the linear model gives better results. The hypothesis of linearity between the examined variables was verified by Ramsey's RESET (Regression Equation Specification Error Test) in the variant including both the squares and the cubes of the variables, and there is no reason for rejecting it (empirical statistical significance $\left.p_{e m p}=0.862\right)^{1}$.

According to White's test, we can say that there is no reason for rejecting the hypothesis regarding the homoscedasticity of the random factor (empirical statistical significance $p_{e m p}=0.520$ ). The Jarque

\footnotetext{
1 All calculations have been made with the GRETL econometric package.
} 
- Bera test confirms that it is pointless to reject the hypothesis regarding the consistency of the random factor distribution with the normal distribution (empirical statistical significance $p_{e m p}=0.121$ ).

Reassuming, model (3) can be regarded as properly specified. In the next stage, an experiment is conducted: one of the explanatory variables $\left(u z_{t}\right)$ is eliminated from model (3), and the model is once again estimated with the dummy variables showing specific attributes of properties in the case of which the hypothesis that the predictive residuals are different from zero should be rejected.

One of the ways of estimating the predictive and studentized residuals is to estimate models of the type:

$$
\begin{gathered}
c_{t}=\alpha_{01}+\alpha_{11} w_{t}+\gamma_{1} z_{1}+\varepsilon_{1 t} \\
c_{t}=\alpha_{02}+\alpha_{12} w_{t}+\gamma_{2} z_{2}+\varepsilon_{2 t} \\
\cdots \cdots \cdots \cdots \cdots \cdots \cdots \cdots \cdots \cdots \cdots \\
c_{t}=\alpha_{0 n}+\alpha_{1 n} w_{t}+\gamma_{n} z_{n}+\varepsilon_{n t}
\end{gathered}
$$

where $\varepsilon_{t}$ is the random factor, and $z_{t}(i=1,2, \ldots, n)$ are the dummy variables equaling one for the $i$-th property and zero - for the remaining ones $(n$ - number of real properties). The assessment of parameter $\gamma_{t}$ is a predictive residual, while the value of the statistic $t\left(\gamma_{t}\right)$ is the respective studentized residual.

In order to identify property specific attributes (different from the ones included in the model), we should find out which residuals differ significantly from zero. Due to the small number of observations, statistical significance is assumed at $\alpha_{p}=0.3$ At this level of significance, the value of the $\mathrm{t}-S t u d e n t$ statistic with the number of the degrees of freedom $n-k=16$ is 1.071 .

Predictive and studentized residuals

Table 2

\begin{tabular}{ccc}
\hline Property & $\begin{array}{c}\text { Predictive } \\
\text { residuals }\end{array}$ & $\begin{array}{c}\text { Studentized } \\
\text { residuals }\end{array}$ \\
\hline $\mathbf{1}$ & $\mathbf{- 3 2 . 2 3 0}$ & $\mathbf{- 1 . 9 3 7}$ \\
\hline 2 & 1.985 & 0.107 \\
\hline 3 & 6.818 & 0.370 \\
\hline $\mathbf{4}$ & $\mathbf{- 3 8 . 9 2 9}$ & $\mathbf{- 2 . 7 5 5}$ \\
\hline 5 & 11.350 & 0.621 \\
\hline 6 & 12.077 & 0.662 \\
\hline $\mathbf{7}$ & $\mathbf{- 2 2 . 2 2 7}$ & $\mathbf{- 1 . 3 6 9}$ \\
\hline $\mathbf{8}$ & $\mathbf{- 2 0 . 5 6 1}$ & $\mathbf{- 1 . 2 5 6}$ \\
\hline 9 & -3.929 & -0.229 \\
\hline 10 & -3.929 & -0.229 \\
\hline 11 & -2.073 & -0.121 \\
\hline 12 & -0.626 & -0.036 \\
\hline 13 & 3.763 & 0.220 \\
\hline 14 & 5.354 & 0.313 \\
\hline 15 & 5.655 & 0.331 \\
\hline 16 & 17.221 & 1.037 \\
\hline 17 & 17.609 & 1.062 \\
\hline $\mathbf{1 8}$ & $\mathbf{2 0 . 5 4 6}$ & $\mathbf{1 . 2 5 5}$ \\
\hline $\mathbf{1 9}$ & $\mathbf{2 2 . 1 2 5}$ & $\mathbf{1 . 3 6 2}$ \\
\hline
\end{tabular}

Residuals differing significantly from zero are in bold. Source: own study. 


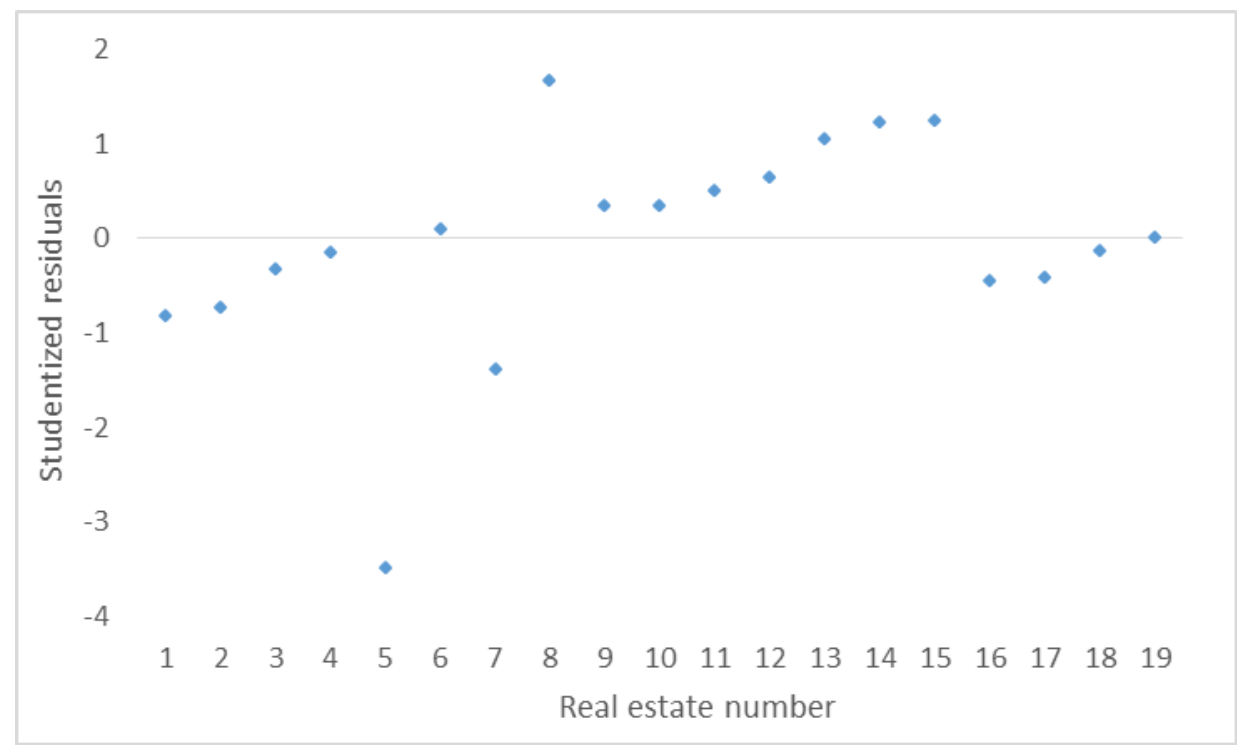

Fig. 1. Studentized residuals. Source: own study.

The relationship between the predictive residuals and the omitted variable $u z_{t}$ (Use Regime and Purpose) can be presented on a correlogram (Fig.2). The predictive residuals also include the impact of random factors (and/or those other than the omitted variable $u z_{t}$ ), nevertheless the relationship shown in Fig. 2 is purely indicative. Despite this constraint, there is a clear positive relationship between these factors.

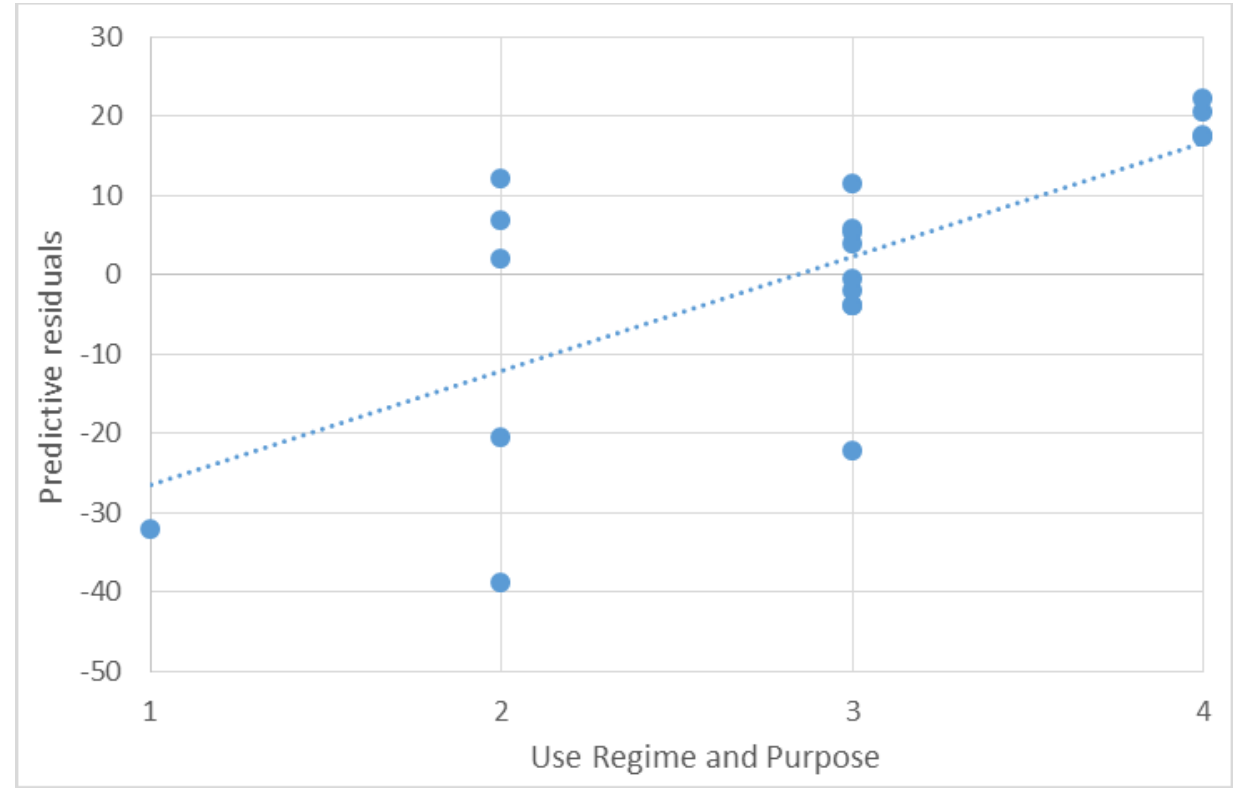

Fig. 2. Relationship between predictive residuals and Use Regime and Purpose (omitted variable $u z_{i}$ ). Source: own study.

At the given level of statistical significance $\left(\alpha_{p}=0.3\right)$, properties No. 1, 4, 7, 8, 18 and 19 display specific attributes. For instance, the regarded as atypical property No. 7 has all of the required utilities and a good use regime. The transaction price of this plot of land was $233.01 \mathrm{zl} / \mathrm{sqm}$. The remaining plots with the same set of these two attributes cost from 250 to over $258 \mathrm{zl} / \mathrm{sqm}$. Hence, it can be said that this particular property had some specific attributes that distinguished it from other plots characterized by similar value-influencing factors.

Model (4), in the form using dummy variables for the observed real properties, is written as: 
On the basis of this model we can say that, in the case of the properties No. 1, 4, 7 and 8, the impact of specific attributes contributed to a decrease in the price of $1 \mathrm{~m}^{2}$ of the plot by an average of 32.23 $\mathrm{zl} / \mathrm{m}^{2}, 40.177 \mathrm{zl} / \mathrm{m}^{2}, 24.668 \mathrm{zl} / \mathrm{m}^{2}$ and $23.120 \mathrm{zl} / \mathrm{m}^{2}$ respectively. The positive impact of specific attributes was observed in the case of the properties No. 18 and 19 (by $15.500 \mathrm{zl} / \mathrm{m}^{2}$ and $16.516 \mathrm{zl} / \mathrm{m}^{2}$ respectively).

Almost all of model (5) parameters are statistically significant at $\alpha=0.05$, with one exception where empirical statistical significance of the parameter is higher than 0.05: $p_{\operatorname{emp}}=0,061>0.05$, which means that there is no reason to reject the hypothesis that the parameter with this variable does not differ significantly from zero. The results of model (5) verification as compared with model (3) have been shown in Table 3.

Table 3

Characteristics of models 3 and 5 (level of fitting of empirical values, values of information criteria, empirical statistical significance levels in the test identifying the homoscedasticity of a random factor with normal distribution)

\begin{tabular}{ccc}
\hline Characteristics & Model (5) & Model (3) \\
\hline $\bar{R}^{2}$ & 0.926 & 0.904 \\
\hline$S_{e}$ & 6.836 & 7.784 \\
\hline$A I C$ & 132.580 & 134.633 \\
\hline BIC & 140.135 & 137.466 \\
\hline$H Q C$ & 133.859 & 135.113 \\
\hline White's test & 0.598 & 0.520 \\
\hline Jarque-Ber test & 0.160 & 0.121 \\
\hline
\end{tabular}

Source: own study.

Interestingly, the above table shows that the model where the variable $u z_{i}$ is replaced by the variables $z_{i}(\mathrm{i}=1,4,7,8,18$ and 19) is better in terms of almost each of the discussed criteria (excluding BIC), i.e. in terms of the fitting of empirical values, the informative criteria $A I C, H Q C$, as well as the empirical significance levels in White's and Jarque-Ber tests².

Here, the question of whether it is possible to define specific attributes of the property in a simpler way arises. For example, can we set the top and bottom lines representing deviations from the average at $20 \%$ of the property value and then identify, on this basis, the properties deviating from this norm? The $20 \%$ deviation from the average had been chosen due to the fact that such a limit is stated in the regulation on property valuation and development of the Valuation Report. The prices of $1 \mathrm{~m}^{2}$ of the plot with levels determined in the above way have been shown in Fig. 3.

It is clear from Fig. 3 that, in this case, when basing on deviations from the arithmetic mean that exceed $20 \%$ of its value, we cannot identify specific attributes of a real property, which is to the benefit of the proposed econometric procedure. Only in the instance of the property No. 1 is the price of $1 \mathrm{~m}^{2}$ lower than the bottom value of the fluctuation band. The prices of the other 18 properties remain in the range of $+/-20 \%$ deviation from the average and, therefore, are not regarded as atypical. Such a simple criterion does not allow for including information whether the price is typical of the particular set of value-influencing factors. It is worth highlighting that the price of property No. 1, which is atypical in terms of its deviation from the average (almost $185 / 1 \mathrm{~m}^{2}$ ), is also considered specific in the light of the proposed method. This means that, in the study sample, the proposed method confirms the "atypicality" of the same real property, as does a simple $20 \%$ interval of price volatility. However, it also allows us to additionally capture other specific attributes of the observed real properties, which is not possible in the case of a simple price criterion.

2 AIC, BIC and HQC are the so-called informative criteria often used when comparing econometric models. According to the approach used in the present paper, the lower the values of these criteria, the better the model. 


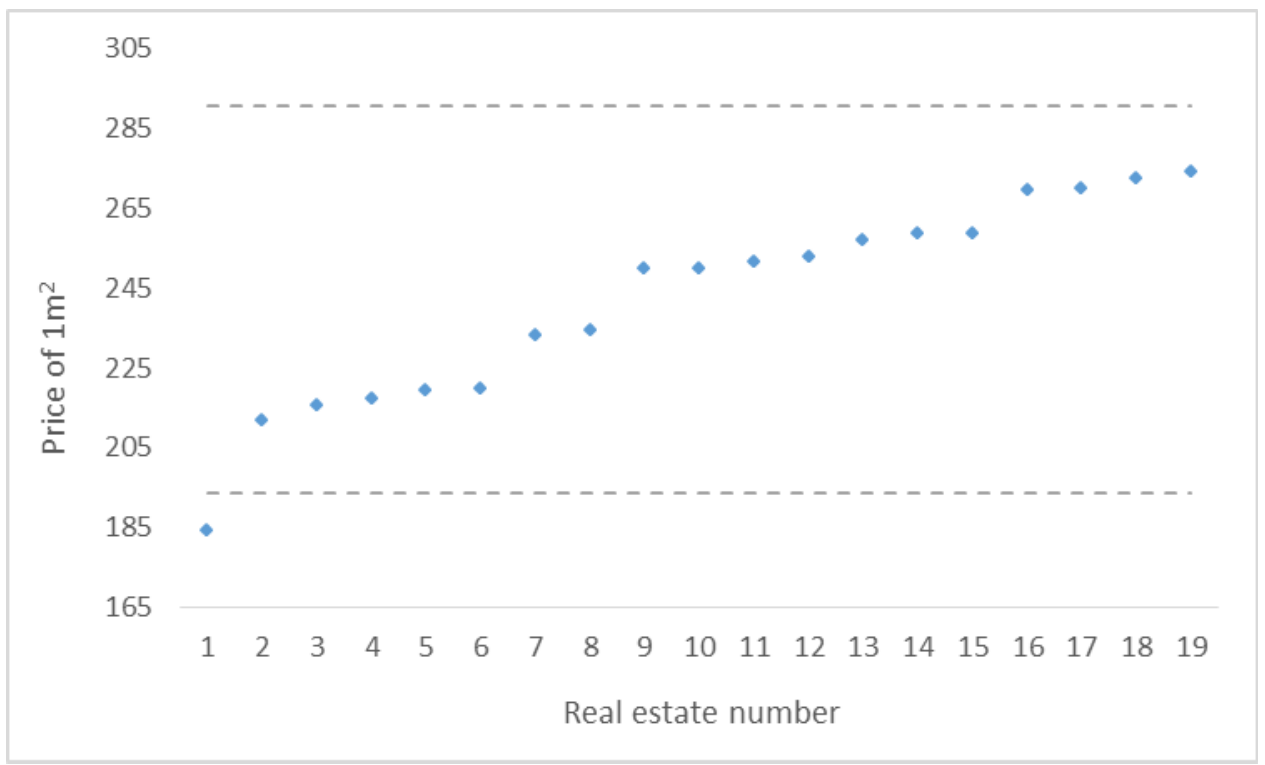

Fig. 3. Price of $1 \mathrm{~m}^{2}$ of a property with top and bottom lines representing the level of deviations from arithmetic mean equaling $20 \%$ of its value. Source: own study.

\section{Conclusions}

As had been mentioned above, it is quite common for real estate market analysts or valuers to face a shortage of information about real properties, which are often greatly diversified in terms of market prices. Even when information concerning the attributes that are typically taken into consideration in valuation reports is available, it often happens that individual properties have unique (specific) characteristics. These specific factors can influence the price, thus affecting (distorting) the valuation results. The paper proposes a method of assessing the impact of the property's specific attributes based on an adequately specified econometric model. The presented results show that the proposed model supports the real estate market analyses performed by valuers during the course of property valuation, supplementing it with an unbiased instrument thanks to which regularities occurring on the real estate market can be more accurately represented by eliminating from the analyzed sets those elements that can disturb the processes of analysis and, consequently, distort its results.

\section{Reference}

ARSLAN Y., KANIK B., KÖKSAL B., 2015, Anticipated vs. Unanticipated House Price Movements and Transaction Volume, Journal of Housing Economics, Vol. 28.

BIN O., 2004, A Prediction Comparison of Housing Sales Prices by Parametric Versus Semi-parametric Regressions, Journal of Housing Economics, Volume 13, Issue 1.

CELLMER R., SZCZEPANKOWSKA K., 2015, Use of Statistical Models for Simulating Transactions on the Real Estate Market, Real Estate Management and Valuation. Vol. 23, Issue 2, pp. 102-111, ISSN (Online) 2300-5289, DOI: 10.1515/remav-2015-0019.

Charemza W.W., Deadman D.F., 1997, Nowa ekonometria (New Econometrics) [in Polish], PWE, Warszawa.

CiCHOCIŃSKi P., DĄBROWSKi J., 2013, Spatio-Temporal Analysis of the Real Estate Market Using Geographic Information Systems, Real Estate Management and Valuation. Vol. 21, Issue 2, pp. 72-82, ISSN (Online) 1733-2478, DOI: 10.2478/remav-2013-0019.

DosZYŃ M., 2013, Skłonności w ekonomii. Ujęcie ilościowe (Propensities in Economy. A Quantitative Approach) [in Polish], Wydawnictwo Naukowe Uniwersytetu Szczecińskiego (Scientific Publishing of the University of Szczecin), Szczecin.

Greene W. H., 2003, Econometric Analysis, Prentice Hall.

HOZER J., KOKOT S., KUŹMIŃSKI W., 2002, Metody analizy statystycznej rynku w wycenie nieruchomości (Methods of Statistical Analysis of the Market in the Valuation of Property) [in Polish], Polska Federacja Stowarzyszeń Rzeczoznawców Majątkowych (Polish Federation of Associations of Real Estate Valuation Experts), Warszawa. 
KIEFER H., 2011, The House Price Determination Process: Rational Expectations with a Spatial Context, Journal of Housing Economics, Vol. 20, Issue 4.

KUCHARKA-STASIAK E., 2010. Odwzorowanie cech nieruchomości w cenach i skutki dla procesu wyceny (Reflection of Real Estate Attributes in Prices and Consequences to the Valuation Process) [in Polish], Studia i Materiały Towarzystwa Naukowego Nieruchomości (Studies and Materials of the Polish Real Estate Scientific Society), 18, No. 3, Olsztyn.

MADDALA G.S., 2006, Ekonometria (Econometrics), Wydawnictwo Naukowe PWN, Warszawa.

PARDOE I., 2008, Modeling Home Prices Using Realtor Data, Journal of Statistics Education Vol. 16, No. 2. 